José Manuel Castro, Jaime Guzmán. Ideas y politica 1946-1973: Corporativismo, gremialismo, anticomunismo, volumen I

(Santiago; Centro de Estudios Bicentenario, 2016).

RESEÑA

\title{
LA PRIMERA ETAPA DE JAIME GUZMÁN
}

\author{
Renato Cristi \\ Wilfrid Laurier University
}

\begin{abstract}
E 1 primer volumen de este sobresaliente trabajo acerca de la vida y E obra de Jaime Guzmán cubre el período comprendido entre 1946 y 1973. El subtítulo de esta obra, "Corporativismo, gremialismo, anticomunismo", resume bien el enfoque de la investigación. Con la mirada puesta en las ideas políticas de Guzmán, José Manuel Castro examina la primera etapa de su vida: el período escolar y universitario, y luego su participación en la campaña presidencial de Jorge Alessandri en 1970 y su oposición al gobierno de Salvador Allende. De partida, Castro presenta a Guzmán como "el colaborador civil más importante del régimen militar y probablemente (...) el personaje más decisivo en la definición del camino político e ideológico asumido por la Junta Militar tras el golpe de Estado de septiembre de 1973" (11). ${ }^{1}$ Esto determina la selección de temas del primer volumen y anuncia la de los próximos volúmenes. El extraordinario acopio de textos que Castro trae a la palestra, el riguroso y detallado análisis que realiza de ellos y la excepcional claridad de su exposición hacen de este libro un gran aporte a la investigación historiográfica chilena.
\end{abstract}

Renato Cristi Becker. PhD en filosofía por la Universidad de Toronto. Profesor del Departamento de Filosofía en Wilfrid Laurier University. Email: rcristi@wlu.ca.

${ }^{1}$ En adelante, la mera numeración entre paréntesis indica la página del libro reseñado: José Manuel Castro, Jaime Guzmán. Ideas y política 1946-1973: Corporativismo, gremialismo, anticomunismo, volumen I (Santiago: Centro de Estudios Bicentenario, 2016). 
El capítulo I se titula "Corporativismo (1946-1962)". Castro toma aquí en cuenta lo que Guzmán publica en la Revista Escolar del Colegio de los Sagrados Corazones y fija principalmente su atención en el ideario corporativista. Éste aparece mencionado en un temprano ensayo de 1962 que Guzmán titula “¡Viva Franco, arriba España!”. Allí describe el sistema político español como nacional-sindicalista y "partidario de una organización corporativa de la sociedad, basada no en partidos políticos, sino en la Familia, el Municipio y el Sindicato, órganos intermedios entre la sociedad y el Estado. (...) Cada una de estas organizaciones elige sus representantes ante las Cortes españolas" (51). El corporativismo es un sistema refractario al liberalismo individualista y los partidos políticos, y, puesto que aparece mencionado en la encíclica Quadragesimo anno, Castro lo denomina "corporativismo católico". Piensa Castro que Guzmán adhiere a esta postura en 1962, pero más tarde, como dirigente universitario, se distancia de ella plegándose al gremialismo (o corporativismo social), por su oposición a la idea que los organismos intermedios tuvieran injerencia política.

En estos primeros ensayos juveniles, Guzmán demuestra ser "un niño fuera de los cánones comunes" (40), que exhibe una inusual consciencia política y un fuerte ánimo contestatario. Castro capta muy bien su cercanía con Osvaldo Lira, a quien destaca por "la claridad de su inteligencia, su voluntad recia y su temperamento apasionado y vehemente" (40). Guzmán debe también a Lira su temprano interés por la filosofía tomista y la adhesión que declara "por el régimen político corporativista" (43). Específicamente, Castro menciona la distinción que hace Lira entre soberanía política y soberanía social, que deriva del carlismo tal como es elaborado por Juan Vásquez de Mella. Esta crucial distinción es también clave de la interpretación histórica de Jaime Eyzaguirre, quien transmite a Guzmán su "entusiasmo por España" (47).

La aproximación histórica que determina el argumento de Castro queda claramente a la vista en las dos primeras secciones del segundo capítulo del libro. Indudablemente, no es posible entender a Guzmán sin tomar en cuenta la efervescencia política y social que genera la revolución cubana, y luego la renovación religiosa que inicia el Concilio Vaticano II. El efecto que tienen en Chile estos sucesos queda de 
manifiesto en el ascenso de la Democracia Cristiana, que culmina con la elección de Eduardo Frei y el inicio de su Revolución en Libertad en 1964. Esto determina el acelerado retroceso de los partidos de derecha. La Iglesia chilena sufre un gran cambio luego de promulgada la constitución apostólica conciliar Gaudium et spes. Muchos católicos, tanto clericales como seglares, buscan "una nueva síntesis entre cristianismo y marxismo", dando origen a movimientos de izquierda cristiana (63).

Castro examina detalladamente la reacción del joven Guzmán frente a esta nueva situación. Ésta queda de manifiesto en sus contribuciones a Fiducia, revista de un grupo de ultraderecha conocido como Tradición, Familia y Propiedad. Este grupo se forma en 1962, luego de conocerse la obra de Plinio Correa de Oliveira, Revolución y contrarrevolución (1959), y de la visita a Chile de uno de sus seguidores en Brasil, Pablo Correa de Brito, a quien Guzmán tiene la oportunidad de escuchar en una charla que da en su colegio. Guzmán publica ocho artículos en Fiducia. Para ellos, Guzmán se inspira en la doctrina social de la Iglesia y particularmente en la encíclica Mater et magistra, a partir de lo cual sintetiza nociones que serán guías cruciales de la actividad política que desarrollará más adelante: subsidiariedad, autonomía de los organismos intermedios, derecho de propiedad e iniciativa privada.

La actividad "política" que emprende Guzmán como alumno de la Facultad de Derecho de la Universidad Católica es estudiaba por Castro en el tercer capítulo de su obra, que titula "Gremialismo (1963-1970)". Guzmán ingresa a la universidad en 1963 como alumno de la Facultad de Derecho. Recién llegado, se le solicita pronunciar un discurso en representación de los alumnos de primer año. De este discurso, Castro selecciona los pasajes decisivos:

Creemos que hoy día el catolicismo de nuestra Patria enfrenta una batalla decisiva en el campo espiritual e intelectual contra enemigos muy poderosos, que han comprendido la transcendencia que reviste la conquista de las esferas universitarias en un avance metódico y progresivo. Y son justamente las Universidades Católicas (...) las que constituyen hoy en día los más firmes bastiones de nuestra causa. (103-104; el énfasis es de Castro)

No puede sorprender que Guzmán participe desde un comienzo en la lucha política al interior de la universidad. En 1963, el sector 
democratacristiano, liderado por Claudio Orrego, presidía la FEUC, imponiéndose por sobre el sector gremialista, que no contaba todavía con una organización comparable. Sólo en marzo de 1967, siendo Guzmán presidente del Centro de Alumnos de Derecho, logra el gremialismo organizarse formalmente como Movimiento Gremial. De su documento fundacional, Castro destaca tres ideas íntimamente relacionadas: autonomía, subsidiariedad y despolitización. Primero, la autonomía universitaria supone que la función esencial de una universidad es el conocimiento y la difusión de la verdad. El documento "A la Escuela de Derecho", emitido luego por el Centro de Alumnos de Derecho, sostiene que la búsqueda del conocimiento es algo que "escapa a toda posición ideológica determinada porque toda ciencia es autónoma en sus métodos y objetivos" (112). Segundo, el principio de subsidiariedad exige que se le asignen al Estado estrictos límites en su tuición sobre la educación superior, quedando su acción reducida, como indica ese documento, a exigir "requisitos mínimos de seriedad e idoneidad requeridos por el bien común, pero de ninguna manera exigiéndole una determinada orientación docente o administrativa" (113). ${ }^{2}$ Finalmente, y como deriva natural de esas dos nociones, la despolitización significa que la universidad y el gremio estudiantil no pueden "subordinarse a ninguna ideología ni partido político" (113). Imposible no ver la mano de Guzmán en la redacción de este documento.

Con respecto a este último punto, Castro comenta: "[A] partir de esta concepción de la despolitización de los cuerpos intermedios, se diferenciaba el campo de acción del poder politico y del poder social, cuestión rechazada por el corporativismo católico" (114). Éste es el argumento central mediante el cual Castro intenta definir el pensamiento político de Guzmán y que tiene, como posible objetivo, distanciarlo del fascismo. En su opinión, esa diferenciación marca el quiebre entre

${ }^{2}$ En un reciente artículo, Carlos Frontaura analiza exhaustivamente el papel que juega el principio de subsidiariedad en la obra de Guzmán. Véase Carlos Frontaura, "Algunas notas sobre el pensamiento de Jaime Guzmán y la subsidiariedad", en Subsidiariedad en Chile: Justicia y libertad, eds. Claudio Arqueros y Álvaro Iriarte (Santiago: Instituto Res Pública y Fundación Jaime Guzmán, 2016), 83-127. También Renato Cristi, "Jaime Guzmán: autor de intención conservadora y acción neoliberal", El Mostrador, 14 de julio de 2016, http://www.elmostrador.cl/noticias/ opinion/2016/07/14/jaime-guzman-autor-de-intencion-conservadora-y-accion-neoliberal/. 
el corporativismo inicial de Guzmán y el gremialismo que él adopta a partir de 1967. ${ }^{3}$ Es también el momento de ruptura con sus maestros Eyzaguirre y Lira, y su rechazo de una democracia orgánica "en la que fueran las organizaciones intermedias las que participaran directa y decisoriamente del poder político" (115). Queda así excluida la posibilidad que "las organizaciones estudiantiles asumieran funciones de representación política" (115).

En la actividad de Guzmán como dirigente estudiantil, Castro pone en evidencia un rasgo determinante de su praxis política que, a mi parecer, tendrá honda significación cuando Guzmán entre a tomar parte de las tareas gubernativas del Régimen Militar, y que arroja dudas con respecto a que esa participación haya sido la de un mero "colaborador" o "asesor". ${ }^{4}$

Bien podría decirse que Guzmán se encargaba de organizar prácticamente todo y no dejaba nada al azar, asignando responsabilidades de todas las funciones implicadas en una campaña política universitaria, tales como las pasadas por sala de los candidatos, revisión de listas de alumnos votantes y adherentes, reuniones en casas para la coordinación general de la campaña, asignación de roles de las jefaturas, confección y distribución de propaganda, coordinación de automóviles para el "acarreo" de votos, telefoneos de contacto, administración de votos, urnas y actas electorales, etc. (119)

El talento historiográfico de Castro queda claramente evidenciado en el capítulo cuarto, titulado "Alessandrismo (1969-1970)". Estudia aquí la participación de Guzmán en el comando electoral de Jorge Alessandri, del que pasaría a ser "una de las principales figuras" (142). Su aporte a esa campaña electoral es esencial, en tanto que influye "en los principales lineamientos políticos que el alessandrismo expresaría du-

${ }^{3}$ Castro sigue a Belén Moncada, quien, por primera vez, intenta distinguir entre el gremialismo de Guzmán y el corporativismo político. Véase Belén Moncada, Jaime Guzmán: El político de 1964 a 1980 (Santiago: RIL, 2006), 49-51.

${ }^{4}$ En mi biografía intelectual de Guzmán utilizo una imagen de Rousseau para afirmar que Guzmán fue el ingeniero que diseñó la máquina, y Pinochet, el fogonero que la echó a andar y mantuvo en movimiento. Véase Renato Cristi, El pensamiento político de Jaime Guzmán: Una biografía intelectual (Santiago: LOM, 2010), 196. 
rante 1970" (146). Su gran aporte es convertir en arma política nacional el ideario gremialista que había logrado imponer en el ámbito universitario. Esto resulta evidente en el borrador de un discurso que Guzmán redacta para Alessandri. Su tema es la "participación popular", eje de su programa electoral, que traduce la noción guzmaniana de poder social. Guzmán se refiere aquí a la necesidad de abrir un "cauce a un nuevo régimen político o institucional". Ese nuevo régimen se presenta como una alternativa al régimen actual, para el que "los partidos políticos [son] prácticamente las únicas instituciones de representación popular" (151). El monopolio partidista debe terminar. Un verdadero "cambio revolucionario" (151) tendrá que permitir la incorporación de los organismos intermedios en el proceso parlamentario. Comienza a perfilarse aquí el temple refundacional de Guzmán.

En otro documento, titulado "Por qué estoy con Alessandri", Guzmán insiste en la idea de un "nuevo régimen institucional que despolitice nuestra vida pública (...) que destierre la intromisión política" (148). Alessandri reitera en la campaña electoral de 1970 lo que había intentado, sin éxito, en 1964: una reforma profunda de la Constitución, que reforzara el poder presidencial y modificara la composición del Parlamento con el objeto de limitar sus atribuciones. El artículo 40 de ese proyecto de reforma modificaba la composición del Senado para que incluyera, de acuerdo con un criterio corporativista, un número de senadores que no fueran elegidos popularmente sino designados por instancias políticas, judiciales, universitarias y gremiales. Lo que, en último término, buscaba esa reforma era modificar el sistema democrático definido por la soberanía del pueblo, que a Alessandri le parecía ingobernable, para reemplazarlo por una democracia que incluyera elementos gremialistas. Notable coincidencia con lo que propondrá Guzmán más tarde.

Castro ilustra magistralmente la enorme influencia que tiene Guzmán en la conducción de la campaña electoral de Alessandri. El viernes 26 de junio de 1970, por ejemplo, Guzmán organiza un gran acto del candidato con la juventud en el teatro Caupolicán. Se esperaba que Alessandri respondiera a once preguntas planteadas de antemano por la juventud.

Así las cosas, Jaime Guzmán — como gran organizador que era - no sólo había sido responsable de efectuar la convocatoria y organizar el programa de la actividad, sino también se encargó 
de redactar esas once preguntas que la juventud plantearía a Alessandri. No quedando el asunto ahí, fue el propio Jaime Guzmán quien preparó el borrador del discurso en el que Alessandri daría respuesta a las once peticiones de la juventud que lo apoyaba. Así, Jaime Guzmán controlaba la entrada y salida de textos alessandristas referentes a la juventud, preparaba las preguntas dirigidas a Alessandri y también las respuestas que el candidato proporcionaba a la juventud, en una suerte de diálogo consigo mismo. (150)

El mismo estilo operativo que Guzmán empleara cuando organizó el movimiento gremialista en la Facultad de Derecho de su universidad lo trasladaría a la campaña electoral de Alessandri.

En el último capítulo, titulado "Gremialismo anticomunista (19701973)", Castro muestra cómo la campaña que dirige Guzmán contra el gobierno de Salvador Allende, campaña que convierte al gremialismo en arma política, lo muestra operando con ese mismo estilo. Tiene razón Castro cuando escribe: "Guzmán se transformaría durante los años 1970-1973 en uno de los personajes públicos más relevantes en la oposición gremial al gobierno del Presidente Salvador Allende y legitimaría el golpe de Estado de las fuerzas armadas de septiembre de 1973" (155). Castro también escribe: “Guzmán articuló 'tras bambalinas' la oposición gremial a la Unidad Popular” (180). Esta observación confirma otro aspecto de su modus operandi, a saber, su preferencia por mantener todo en secreto y proceder anónimamente. ${ }^{5}$

La actividad política que despliega Guzmán contra el gobierno del Presidente Allende se manifiesta "en tres grandes espacios" (168). Primero, Guzmán conserva sus vínculos con la Universidad Católica, tanto a nivel de la directiva gremial estudiantil, como con respecto a la administración universitaria. Es profesor de la Facultad de Derecho y miem-

${ }^{5}$ Castro se refiere al libro de Verónica Valdivia, Nacionales y gremialistas: El "parto" de la nueva derecha política chilena, 1964-1973 (Santiago: LOM, 2008), de modo que resulta extraño que no tome en cuenta las columnas que Guzmán publica en la revista PEC, desde 1971 en adelante, bajo el seudónimo "Juglar" (página 255 de Valdivia). Más tarde, entre 1979 y 1983, publicará anónimamente numerosos editoriales para la revista Realidad. Estos editoriales son indispensables para articular las claves conceptuales de su pensamiento político. En 1973, publica también dos artículos en la revista carlista Tizona bajo el seudónimo "Julio García E.". Ver Cristi, El pensamiento político, 213 y ss. 
bro de su consejo académico; es también parte del consejo superior de dicha universidad y del directorio de Canal 13. Durante el paro de julio y agosto de 1973, que cuenta "con la participación articuladora de Jaime Guzmán" (185), se les ofrece a los camioneros huelguistas dependencias de la Casa Central de esa misma universidad. Aunque Castro no lo menciona, resulta también innegable la participación de Guzmán en la declaración pública de la FEUC y la Federación de Estudiantes de la Universidad Católica de Valparaíso (FEUC-V), titulada "Hacia una nueva institucionalidad a través de la renuncia de Allende", que se publica en El Mercurio, el 30 de agosto de 1973. Esta declaración llama abiertamente a la intervención de las fuerzas armadas. Los términos en que está planteada coinciden perfectamente con la estrategia refundacional que Guzmán deriva del carlismo. Un pasaje de la declaración afirma que "la tradicional institucionalidad chilena hoy virtualmente no existe", y no es posible seguir defendiéndola porque "en la práctica ha muerto" (188). En 1975, ocupará el mismo lenguaje cuando se refiera al destino de la Constitución de $1925 .^{6}$

Segundo, como consecuencia de dirigir el comando electoral de Alessandri, Guzmán logra formar "una red de conexiones que se [extiende] por todo el territorio de Chile" (169). Según Castro, los sectores juveniles del alessandrismo tendrán influencia en el movimiento Patria y Libertad, del que Guzmán es cofundador y miembro activo hasta 1972. La ruptura de Guzmán con Patria y Libertad tiene que ver con su oposición al corporativismo político que adopta este movimiento. Es cierto que Guzmán acepta la "importancia de crear nuevas formas de acción cívico-política", pero no concuerda con la idea de que los gremios participen en las tareas legislativas del Parlamento (177). Reconoce Castro, sin embargo, que Guzmán se encontraba "a medio camino entre un estricto gremialismo (...) [y] un corporativismo político" (177).

Y tercero, Castro destaca la participación de Guzmán en la prensa, radio y televisión con lo que sus ideas logran un "alcance nacional" (169). Es panelista del programa televisivo A esta hora se improvisa; participa en un programa matinal de radio Agricultura; es columnista de PEC y miembro del comité editorial de las revistas de derecha Portada y

\footnotetext{
${ }^{6}$ Cristi, El pensamiento político, 104.
} 
Qué Pasa. Castro nota que la presencia activa de Guzmán en los medios de comunicación es anterior al gobierno de Allende. En un artículo suyo en Portada, "El miedo: síntoma de la realidad político-social chilena", publicado en 1969, se vislumbra ya la idea de una nueva institucionalidad para Chile. Señala que la tendencia estatista del gobierno de Frei no es un problema que pueda solucionarse con un mero cambio de gobierno. En una confirmación de su ánimo refundacional, Guzmán escribe:

Alguien podría pensar que gran parte de la solución reside en el cambio del actual Gobierno. Pero ello no es sino una parte muy limitada de la solución (...), aun cambiado el Gobierno, la amenaza de una nueva aventura de miedo colectivo — acaso todavía peor- seguirá latente.

Sólo el abandono del camino estatista puede solucionar el problema por su misma base. ${ }^{7}$

Castro concluye el capítulo quinto aludiendo al llamado que la FEUC y la FEUC-V del 30 de agosto de 1973, el que exige la renuncia de Allende, aboga por una intervención militar y define un camino político refundacional "que tuviera como objetivo la construcción de un nuevo orden institucional" (188). Castro también reconoce que, luego del golpe, Guzmán hará efectivo el ideario gremialista que había articulado en su juventud, y que había logrado difundir y hacer realidad en vastos sectores de oposición a la Unidad Popular.

En la conclusión de su libro, Castro anticipa el argumento de los volúmenes por publicarse. En ella escribe:

El estudio de la evolución de esas ideas políticas [de Guzmán] permite comprender el significado que tuvo la expresión de ellas

${ }^{7}$ Texto recogido en Arturo Fontaine Talavera, "El miedo y otros escritos: El pensamiento de Jaime Guzmán E.”, Estudios Públicos 42 (1992): 259. Castro cita parcialmente este texto (172). Al omitir la parte en que Guzmán se refiere a la necesidad de ir más allá de un cambio de gobierno, no toma en cuenta que ya en 1969 propicia una nueva institucionalidad política, es decir, la creación de una nueva constitución. 
durante el régimen de Pinochet. La participación de Jaime Guzmán como asesor civil de ese gobierno marcó el punto de llegada de toda una trayectoria de reflexión política desarrollada por el líder gremialista, iniciada durante su paso por los Sagrados Corazones (...) y culminada en su colaboración como miembro de la Comisión Ortúzar y la promulgación de la Constitución Política de 1980, lo que será tratado en un segundo libro (189; el énfasis es mío).

Y más adelante agrega: "Entre 1973 y 1980 Guzmán participaría como asesor constitucional de la Junta de Gobierno y desde 1980 sería un actor fundamental en el proceso de transición política a la democracia" (193; el énfasis es mío). Esto coincide con el lenguaje que usa Castro en la introducción de su libro, para describir la actividad de Guzmán entre 1973 y 1978. Castro se refiere ahí a "la crucial participación de Jaime Guzmán en la Comisión de Estudios de la Nueva Constitución” (12).

Me parece legítimo que Castro haya limitado su investigación al estudio de "las ideas políticas de Guzmán en su formulación y en el marco de una praxis política", y no lo haya presentado en el marco "de la teoría política" (13). Proceder de esta manera en un estudio de la etapa juvenil de Guzmán podría resultar plausible. No creo, sin embargo, que esta "abstención teórica" pueda rendir frutos suficientes cuando Castro examine, en los siguientes volúmenes, la participación que le cabe a Guzmán en la formación del Régimen Militar de Pinochet, particularmente en lo referido a la destrucción de la Constitución de 1925 y la creación de una nueva institucionalidad gremialista. El anuncio de Castro que cito más arriba no me parece una buena señal al respecto. El escenario que presenta ese anuncio enfatiza la iniciativa y el papel que juega Pinochet en la creación de la nueva institucionalidad, dejando a Guzmán como un mero colaborador en esas tareas, como un asesor de decisiones que toman otros agentes principales. Castro presenta a Guzmán como un miembro más de la "Comisión de Estudios de la Nueva Constitución", a la que también denomina "Comisión Ortúzar". No toma en cuenta que la denominación original de esa comisión es "Comisión Constituyente". El apelativo "constituyente" describe más adecuadamente el sello refundacional que le otorga Guzmán a la comisión. Es en ella que Guzmán, por medio del Decreto Ley n. ${ }^{\circ} 128$, de noviembre de 1973, designa a Pinochet y la Junta Militar como sujetos del poder constituyente originario. Esta temeraria decisión debe ser atribuida 
derechamente a Guzmán y es posible caracterizarla como en sí misma constituyente. Hay que tener en cuenta, además, que el hecho de que la comisión sea presidida por Enrique Ortúzar no obsta para considerar a Guzmán su miembro principal. Guzmán es quien lidera el proceso constituyente al que define como un proceso refundacional. ${ }^{8}$

Para dar cuenta de las ideas y principios que Guzmán pone en juego durante todo este proceso, me parece indispensable una consideración teórica. Es sólo teóricamente que se pueden identificar y definir nociones tales como poder constituyente originario y derivado, proceso constituyente, principio monárquico, legitimidad monárquica y democrática, normativismo y decisionismo schmitteano, estado de excepción, dictadura comisaria y soberana. Hay que considerar, además, la constelación de ideas que guían el proceso constituyente que lidera Guzmán; a saber, prioridad ontológica y de finalidad de la persona, bien común, propiedad privada, subsidiariedad, poder social y poder político, corporación, gremio, libertad, autoridad, etcétera. Estas son las claves conceptuales que se emplean para crear la nueva institucionalidad que encarnará la Constitución de 1980. Un ejercicio conceptual como el que he propuesto es lo que permite entender cabalmente el pensamiento político de Guzmán. He definido este ejercicio como una biografía intelectual. Pero, en ningún caso, he usado el término "intelectual" para significar que Guzmán sea preponderantemente él mismo un intelectual,

${ }^{8}$ Guzmán adopta una actitud refundacional, porque, inspirado en el carlismo de Lira y Aniceto de Castro, privilegia la legitimidad de ejercicio por sobre la legitimidad de origen. En su memoria de prueba (1970) cita a Aniceto de Castro: "Un consentimiento tácito, una callada adhesión, un mero gobierno en paz y sin protestas, en régimen de justicia, de legítima libertad y de amplia conformidad ciudadana, son indicios suficientes de un refrendo popular, que basta para lavar al poder de su pecado de origen" (Jaime Guzmán y Jovino Novoa, "Teoría sobre la universidad" (1970), memoria de prueba, Facultad de Derecho, Universidad Católica de Chile, xix). También cita (ibídem) a Lira, quien escribe: "La trascendencia de la legitimidad de adquisición [o de origen] es de muy escasa monta si se considera en sí misma e independientemente de las consecuencias que su violación en un momento determinado podría producir en una sociedad" (Osvaldo Lira, Nostalgia de Vásquez de Mella (Santiago: Editorial Difusión, 1942), 173). Este texto muestra la predisposición golpista de Guzmán y su intento, más tarde, de lavar el pecado de origen de la dictadura militar de Pinochet y su destrucción de la Constitución del 25. Esa predisposición, típica del carlismo, la confirma Lira cuando escribe: "El problema de la legitimidad del poder tiene su transcendencia porque lleva consigo como correlativo el de lo lícito de la sublevación" (ibídem, 173). 
sino sólo para indicar la necesidad de realizar un estudio intelectual de sus ideas durante el curso de su vida.

Un esclarecimiento conceptual puede dar cuenta, además, de ciertas inconsistencias en el argumento de Castro. Una de las claves de su libro es la distinción que introduce entre corporativismo y gremialismo. ${ }^{9}$

El corporativismo sería esencialmente un corporativismo político, al que también caracteriza como "corporativismo católico". Ésta es la idea matriz que Guzmán habría heredado de Lira y Eyzaguirre. Lira, por ejemplo, les reconoce a organizaciones intermedias, como municipios y gremios, la "capacidad para representar sus intereses en una institución como las Cortes u otra instancia de representación popular" (43). Para Castro, el gremialismo sería un corporativismo puramente social, que reconoce la autonomía de lo político y no permite la participación directa de los gremios, particularmente de los gremios estudiantiles, en el poder político. Guzmán habría adherido al corporativismo político en un comienzo para muy luego abandonarlo en favor del gremialismo. Pero Castro no deja bien en claro cuándo exactamente ocurre esa transición. Afirma que en los artículos de Guzmán para Fiducia, en 1965, se encuentra "el último vestigio del corporativismo católico propiamente tal en su pensamiento" $(115,190)$. Pero el corporativismo político aparece nuevamente cuando Guzmán inicia su participación en la campaña electoral de 1970. Para evitar esta dificultad Castro separa esa actividad en dos frentes: el político y el gremial (168). Pero en 1972 esa separación colapsa cuando Guzmán declara la necesidad "de incorporar a las decisiones nacionales a los organismos intermedios" (177). Para reafirmar su tesis, Castro observa que esa declaración de Guzmán "omitía una valoración del corporativismo político" (177), y fundamenta su observación de la siguiente manera: "El rol no político que los gremios debían jugar no era contradictorio con su participación en la esfera pública, debido a 'la naturaleza preponderantemente técnica, y no ideológica, de los problemas contemporáneos"' (177). El hecho que para Castro no sea contradictorio extender a la política el radio de acción del gremialismo echa por tierra la

${ }^{9}$ Esto coincide con la distinción que introduce Paul Drake entre un corporativismo social o natural y un corporativismo político o artificial. Véase Paul Drake, "Corporatism and Functionalism in Modern Chilean Politics", Journal of Latin American Studies 10 (1978); y Philippe Schmitter, "Still the Century of Corporatism?", en The New Corporatism, eds. Frederick Pike y Thomas Stritch (Notre Dame: Notre Dame University Press, 1974). 
separación que intenta mantener entre corporativismo político y gremialismo. El corporativismo político reaparece nuevamente cuando Castro observa que Guzmán, durante su militancia en Patria y Libertad, adhiere a una declaración que resalta la "importancia de crear nuevas formas de acción cívico-política". Castro admite que, en ese momento, Guzmán se posiciona a "medio camino" entre el corporativismo y el gremialismo (177), lo que confirma, a mi entender, el colapso de esa separación.

Castro no toma en cuenta que el corporativismo de Lira y Eyzaguirre es de inspiración carlista y, como tal, busca mantenerse a cierta distancia del fascismo. El fascismo favorece la secularización y exalta la autoridad absoluta de un Estado totalitario. El carlismo, en cambio, pone límites a la acción del Estado exaltando la soberanía social de municipios, regiones y corporaciones nacionales. Es además ultracatólico, lo que implica que el Estado debe toparse también con el límite que significa reconocer la superioridad espiritual de la Iglesia. Los carlistas admiran a Salazar en Portugal, a Dollfuss en Austria y a Degrelle en Bélgica, pero se distancian de Mussolini y, sobre todo, de Hitler. ${ }^{10}$ Por su parte, Lira ve en el carlismo un movimiento conservador, esencialmente contrarrevolucionario, que aspira a refundar la sociedad y la cultura de acuerdo a un ideario que rescata de la Edad Media. Las Cortes que considera tienen que ver mucho más con los parlamentos medievales de representación estamental o de clases, que con las cámaras corporativas fascistas. ${ }^{11}$ El totalitarismo que teme Lira lo conduce a "diferenciar" entre el poder político y el poder social, y en ningún caso aspira a su "integración”, como piensa Castro (14).

La estrategia de Castro, que es ver una evolución en Guzmán que avanza desde un corporativismo político a un gremialismo puramente social, no cuadra con la inspiración carlista de su gremialismo. Al igual que Lira y Eyzaguirre, el corporativismo de Guzmán no evoluciona; es

${ }^{10}$ Martin Blinkhorn, Carlism and Crisis in Spain: 1931-1939 (Cambridge: Cambridge University Press, 1975), 144-45.

${ }^{11}$ El ideario corporativista de Lira sigue a Juan Vásquez de Mella y, sobre todo, a Víctor Pradera, quienes promueven la restauración de una sociedad de corte feudal articulada naturalmente en seis clases sociales fundadas orgánicamente en la agricultura, la industria, el comercio, la propiedad, las profesiones liberales y el trabajo manual (Blinkhorn, Carlism and Crisis, 149). En la conclusión de su libro El Estado nuevo, Pradera puede afirmar: "En este estudio del Estado nuevo (...) hemos descubierto que el nuevo Estado no es otro que el Estado español de los Reyes Católicos" (Víctor Pradera, El Estado nuevo (Madrid: Cultura Española, 1941), 276). 
siempre gremialista y, por ello, antiestatista y antitotalitario. ${ }^{12}$ Guzmán no tiene reservas con respecto a la idea de una economía capitalista. Rechaza sólo la pretensión totalitaria del liberalismo de imponer una sociedad capitalista. Defiende así lo que interpreta como el capitalismo orgánico y corporativo de las encíclicas. El capitalismo que repudia es el capitalismo liberal, que concibe como un "monstruoso fenómeno histórico" y que coincide con "la decadencia de la Edad Media" y la pérdida de los "sólidos ejes sobre los cuales se había estructurado una sociedad orgánica". ${ }^{13}$ Queda por ver si esto constituye un anticipo de su futura conciliación con el neoliberalismo hayekiano.

Finalmente, debo admitir que Castro tiene razón cuando afirma que "Guzmán no era un intelectual sino un político", y que su labor "no se movió exclusivamente en el plano de las disquisiciones teóricas de la filosofía política, sino eminentemente en el campo de la deliberación política" (13). ${ }^{14}$ Es más, yo diría que Guzmán no se contentó con la

12 En 1981, Guzmán admitiría que Franco mismo no fue del todo corporativista. Escribe: "Incluso la propia Falange española terminó sintiéndose traicionada por Franco, no obstante las amplias concesiones — si bien más formales que reales- que éste realizó al esquema corporativo" (Jaime Guzmán, "Nacionalismos y totalitarismos", Realidad 3, n. ${ }^{\circ} 27$ (1981): 12).

13 Jaime Guzmán, "El capitalismo y los católicos de tercera posición”, Fiducia III, n. ${ }^{\circ} 20$ (1965): 5.

${ }^{14}$ Hugo Herrera formula un argumento similar cuando afirma que en Guzmán encontramos "un amasijo de doctrinas heterogéneas entre sí. Él mismo tiene que reconocer inconsistencias, incluso dentro de un mismo texto (...). ¿Cabe seguir hablando de un 'pensamiento político' o hay que reconocer, en cambio, que la yuxtaposición de doctrinas hábilmente asumidas y desechadas según las circunstancias y bajo el imperativo de la libertad del cristiano es lo que mejor caracteriza su actitud?" (Hugo Herrera, "Derecha y comprensión política: respuesta a Joaquín Fermandois, Renato Cristi y Max Colodro", Estudios Públicos 139 (2015): 252). Me parece que Herrera no observa que la unidad del pensamiento político de Guzmán viene dada por su permanente y fiel adhesión a la doctrina social de la Iglesia, algo que he sostenido reiteradamente como punto central en mis escritos acerca de Guzmán. Lo paradójico es que Guzmán privilegia la lectura de Rerum novarum y no considera la evolución del pensamiento pontificio a partir de esa encíclica. Por lo demás, el sentido de este documento podría caracterizarse como constituyendo, en la caracterización de Carl Schmitt, una complexio oppositorum. En la recepción de León XIII de la idea de propiedad privada de Locke podría encontrarse un antecedente de la síntesis que logra Guzmán entre catolicismo y neoliberalismo. En último término, lo de "yuxtaposición de doctrinas hábilmente asumidas y desechadas según las circunstancias" podría aplicarse a la doctrina social de la Iglesia. Esa doctrina, por ejemplo, adhiere al corporativismo en 1931, para desecharlo más adelante. 
deliberación política, sino que fue un político que supo decidir. Por ello mismo, me resulta difícil considerarlo como un mero "asesor" o "colaborador" en las decisiones de otros. No me parece inapropiado definirlo como el Portales de Pinochet. ${ }^{15}$ Guzmán fue un político de ideas y de decisiones globales. Por tanto, me parece pertinente un análisis teórico que tenga en cuenta el pensamiento político de un pensador de tendencia eminentemente práctica y decisoria.

\section{BIBLIOGRAFÍA}

Blinkhorn, Martin. Carlism and Crisis in Spain: 1931-1939. Cambridge: Cambridge University Press, 1975.

Castro, Aniceto de. El derecho a la rebeldia. Madrid: Gráfica Universal, 1934.

Cristi, Renato. "El constitucionalismo autoritario de Jaime Guzmán". En La República en Chile: Teoría y práctica del constitucionalismo republicano, editado por Renato Cristi \& Pablo Ruiz-Tagle. Santiago: LOM, 2006.

—. El pensamiento político de Jaime Guzmán: una biografía intelectual. Santiago: LOM, 2010.

—. "Jaime Guzmán: autor de intención conservadora y acción neoliberal", El Mostrador, 14 de julio de 2016. http://www.elmostrador.cl/noticias/ opinion/2016/07/14/jaime-guzman-autor-de-intencion-conservadora-y-accionneoliberal/.

Drake, Paul. "Corporatism and Functionalism in Modern Chilean Politics". Journal of Latin American Studies 10 (1978): 83-116.

Fontaine Talavera, Arturo. "El miedo y otros escritos: El pensamiento de Jaime Guzmán E.”. Estudios Públicos 42 (1992): 251-570.

Frontaura, Carlos. "Algunas notas sobre el pensamiento de Jaime Guzmán y la subsidiariedad". En Subsidiariedad en Chile: Justicia y libertad, editado por Claudio Arqueros \& Álvaro Iriarte. Santiago: Instituto Res Pública \& Fundación Jaime Guzmán, 2016.

Guzmán, Jaime. “¡Viva Franco, arriba España!”. Revista Escolar 54 (1962): 15-18. . "El capitalismo y los católicos de tercera posición". Fiducia III, n. ${ }^{\circ} 20$ (1965): 4-5.

__. "Nacionalismos y totalitarismos". Realidad 3, n. ${ }^{\circ} 27$ (1981): 10-12.

. "Entre O'Higgins y Prieto: Pinochet ante un dilema histórico". Realidad 4, n. ${ }^{\circ} 40$ (1982): 3-6.

${ }^{15}$ En 1982, Guzmán deja en claro el papel portaliano que decidió representar. Véase Jaime Guzmán, “Entre O’Higgins y Prieto: Pinochet ante un dilema histórico", Realidad 4, n. ${ }^{\circ} 40$ (1982): 3-6. 
Guzmán, Jaime \& Jovino Novoa. "Teoría sobre la universidad". Memoria de prueba, Facultad de Derecho, Universidad Católica de Chile, 1970.

Herrera, Hugo Eduardo. "Derecha y comprensión política: respuesta a Joaquín Fermandois, Renato Cristi y Max Colodro”. Estudios Públicos 139 (2015): 239-258.

Lira, Osvaldo. Nostalgia de Vásquez de Mella. Santiago: Editorial Difusión, 1942.

Moncada Durruti, Belén. Jaime Guzmán: El político de 1964 a 1980. Santiago: RIL, 2006.

Pradera, Víctor. El Estado nuevo. Madrid: Cultura Española, 1941.

Schmitter, Philippe. "Still the Century of Corporatism?". En The New Corporatism, editado por Frederick Pike y Thomas Stritch. Notre Dame: Notre Dame University Press, 1974: 85-131.

Valdivia, Verónica. Nacionales y gremialistas: El "parto" de la nueva derecha política chilena, 1964-1973. Santiago: LOM, 2008. EP 